\title{
Mechanical Study on the Traumatic Optic Nerve Injury
}

\author{
Kimiyoshi Hrrakawa, Keizo Hashizume, \\ Norio Nakamura and Keiji Sano \\ Department of Neurosurgery, University of Tokyo, Tokyo, Japan
}

Optic nerve injury or blindness after head trauma has well been known since the days of Hippocrates, and has still remained one of the serious posttaumatic sequelae. Statistically about $2 \%$ of head-injured persons suffer from the visual loss and are impelled to have limited social activites ${ }^{3)}$. As the victims of traffic accidents are increasing every year, the studies about this problem are urgent.

Clinical manifestations of the injury of the optic nerve have been well known. The reports of many institutions have shown almost the same results. The summaries are as follows ${ }^{3)}$ : There is a constant mode of trauma to make an injury. It occurs frequently in motorcycle accidents. Sometimes it occurs even in trivial accidents, where impact force is not always so large. The blow is usually given to the front of the head. Symptomatologically visual loss occurs immediately after the trauma and is limited usually to the eye on the ipsilateral side to the impact and spares the eye on the contralateral side. Diagnosis is guided from the loss of direct light reflex of the affected side. The fracture of the optic canal is often visualized in X-ray studies. Surgical intervention is not fully effective.

From the pathological view point, there are so many therories as to the causative factors of the injury of the optic nerve. The fracture of the optic canal, the bleeding of the sheath of the optic nerve, and the tearing of nerve fibers are prominent among them. Fracture theory seems most attractive because the fracture of the optic canal is found in $60-90 \%$ cases in X-ray studies.

So far, these clinical and pathological data have strongly suggested that mechanical factors play an important role to cause the lesion. However, there has never been a fundamental engineering study. Therefore in this paper, mechnical studies were performed to investigate the mechanism and to clarify the threshold of the impact force of the fracture of the optic canal, which is thought to be closely relevent to the ipsilateral optic nerve injury. The studies were made up of series of experiments.

\section{Experments and Results (I) The fracture of the optic canal}

1) Stress coat experiments

Stress coat method was used in the first experiments. Stress coat ${ }^{5)}$ (DailerKansai Paint Co.) was lacqured to human dried cadaver skulls over the entire outer and inner surface of the skulls including the orbits. The skulls were compressed statically in a compressor of Amsler type or were dropped onto the floor, to cause an im- 


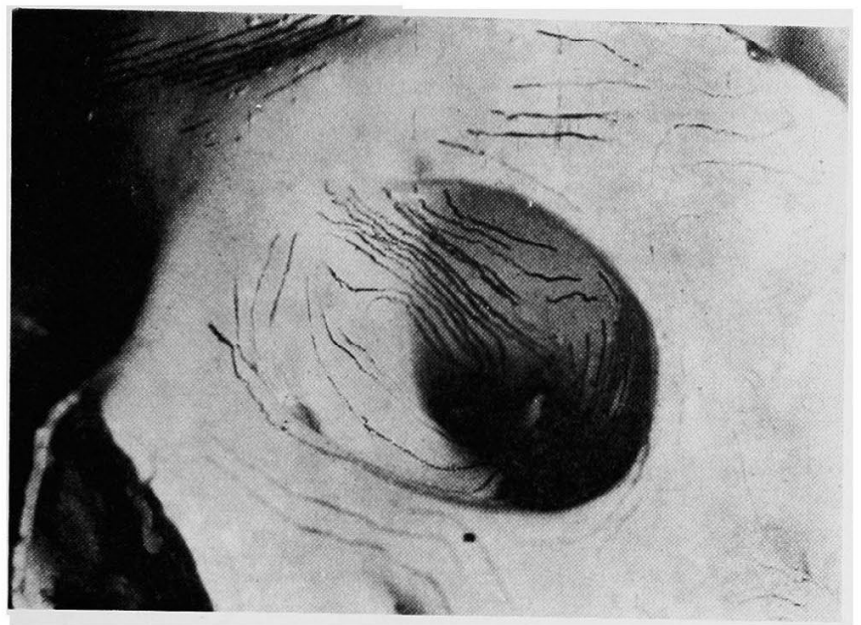

Fig. 1 Stress lines appeared on the roof of the orbit on the ocular side towards the optic canal. The lines were traced by a pencil.

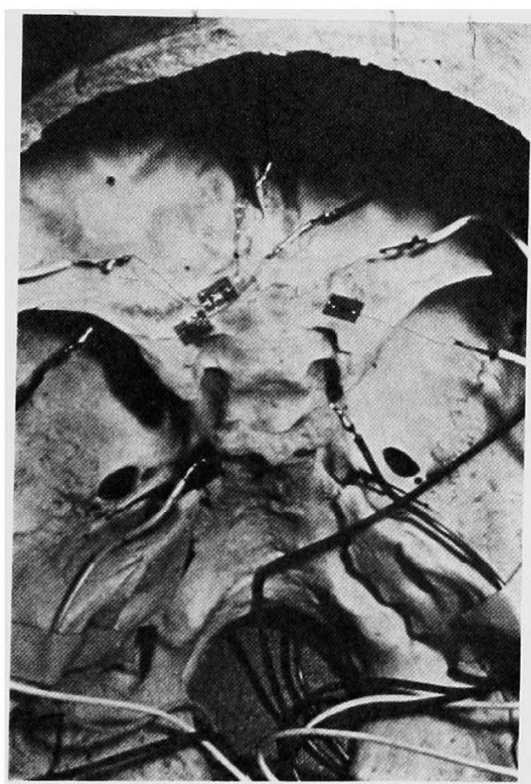

Fig. 2 Strain gauges were applied to the bilateral upper walls of the optic canals on the brain and the ocular sides.

pact force to the skull in the frontal areas. Then, stress lines appeared just on the roof of the orbit toward the optic canal on the ipsilateral side of the blow (Fig. 1).

The stress lines of the orbital roof on the side of the brain and of the eye ball were compared, and it was supposed that the roof of the orbit and the optic canal were depressed from above at the moment of impact. 


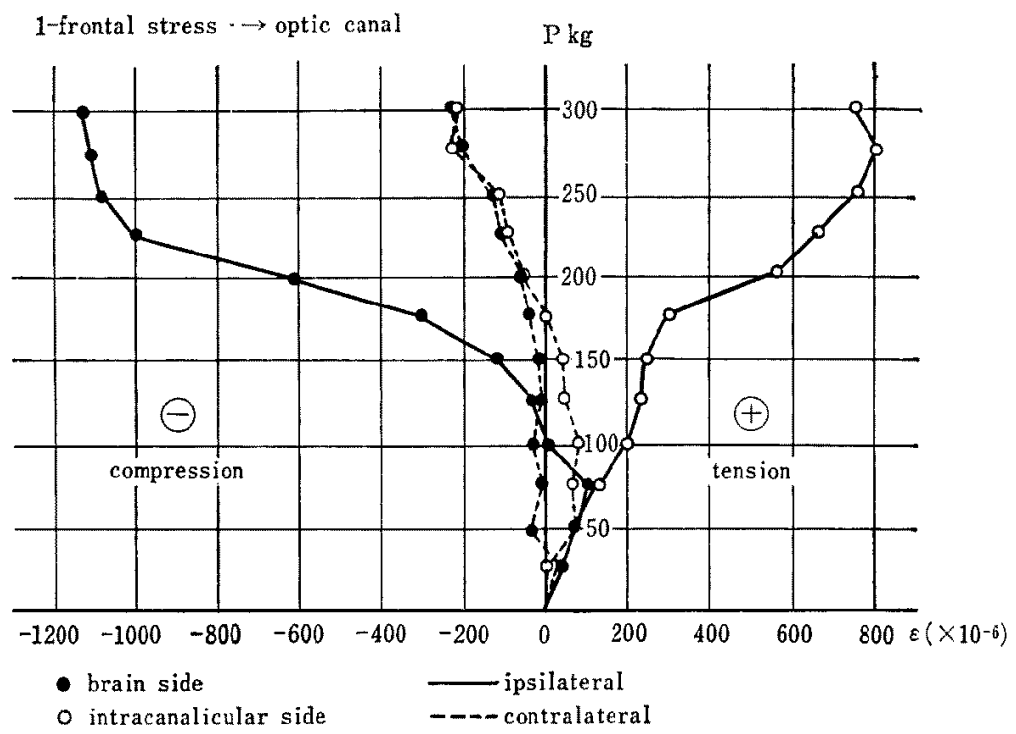

Fig. 3 Stress-strain curve (3)

2) Static compression tests

To comfirm the above-mentioned results, strain gauges were patched bilaterally to the upper walls of the optic canals, each on the brain side and on the ocular side (Fig. 2). The skulls were compressed statically and obliquely from one side of the front to the counter side of the occiput. The strains were recorded by a strain meter, and stress-strain curves were drawn.

Strains were recorded especially on the compressed side, showing that the upper wall of the optic canal was bent downwards, while the other side showed little effect of strain (Fig. 3). There were a few exceptions where the canal was warped in the lateral portion, the wall of which is facing the air sinus. The skulls were destroyed by $300-500 \mathrm{~kg}$ load.

\section{3) Dynamic impact tests}

Dynamic tests were added. Strain gauges were patched in the same manner as in the static tests. Intracranial spaces were filled with $5 \%$ gelatin instead of the brain, and the skulls were covered with $4 \mathrm{~mm}$ silicon rubber skin ${ }^{6}$ ). The heads were dropped from various heights on a steel plate. The apparatus of dropping is given in Fig. 4. The heads were attached to the end of a guide bar by holding hooks. The bar was dropped passing through the holes settled in the guide boards which were attached rectangularly to the vertical wall. The weights of the heads were 2.0-2.3 $\mathrm{kg}$ and total weights with guide bars were $3.2-3.6 \mathrm{~kg}$. The results were almost the same as those of the static experiments. Compression strains were obtained on the upper wall of the optic canal on the brain side, and tensile strains on the inner wall of the canal. Fractures of the vault occurred in 60-100 cm fall on the stecl plate. 


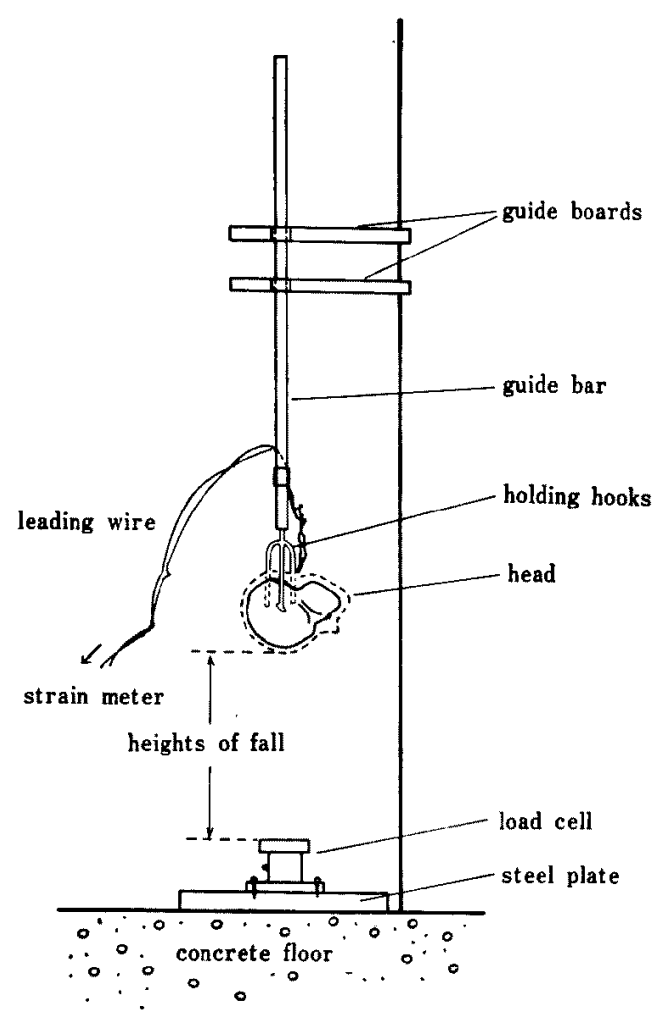

Fig. 4 The apparatus of dynamic impact tests.

Maximum load factor or mean acceleration was greater than 110. The optic canals were destroyed in $20-60 \mathrm{~cm}$ fall and the load factor was about 70-100. So the upper wall of the optic canal was more easily fractured than the skull of the vault.

4) Bending tests of the upper wall of the optic canal

Bending tests were performed on the bone of the upper wall of the optic canals in 19 autopsied cases and the results were compared with those of the bone of the vault in 14 operative materials. Precise methods of the bending test and the calculation are omitted here for simplification ${ }^{3)}$. In short, strains on each side of the test pieces were recorded by a strain meter until the bones broke with snap. The cut surface of the broken bone were magnified by projecting to a screen. Then, the values of the principal lst and 2nd moment of area were calculated by a integrator from the sectional views. The answers were obtained from the formula. Table 1 shows the summary of the results. Young's modulus was $172 \mathrm{~kg} / \mathrm{mm}^{2}$ and bending strength was $0.6 \mathrm{~kg} / \mathrm{mm}^{2}$ on the average. The former was about half and the latter was one-tenth of the corresponding value of the vault of the skull, for which experiments had been performed before (Table 2). Table 3 shows comparison of various materials.

The upper wall of the optic canal varies in thickness $(0.4-2.7 \mathrm{~mm})$. In some 
Table 1 Bending test of the upper wall of the optic canal

\begin{tabular}{rcccc}
\hline Material & Age \& sex & $\begin{array}{c}\text { Thickness } \\
(\mathrm{mm})\end{array}$ & $\begin{array}{c}\text { Young's } \\
\text { modulus } \\
\left(\mathrm{kg} / \mathrm{mm}^{2}\right)\end{array}$ & $\begin{array}{c}\text { Bending } \\
\text { strength } \\
\left(\mathrm{kg} / \mathrm{mm}^{2}\right)\end{array}$ \\
\hline 1 & 56 male & 1.2 & 196 & 0.48 \\
2 & 43 male & 0.7 & 139 & 0.18 \\
3 & 62 male & 2.7 & 302 & 1.15 \\
4 & 48 male & 1.2 & 285 & 1.09 \\
5 & 32 male & 2.0 & 94 & 0.56 \\
6 & 57 male & 0.4 & 9 & 0.13 \\
7 & 59 male & 3.1 & 221 & 0.42 \\
8 & 45 male & 1.1 & $598^{*}$ & 0.83 \\
9 & 68 male & 1.4 & 108 & 0.43 \\
10 & 52 male & 1.9 & 309 & 0.90 \\
11 & 47 male & 1.1 & 214 & 1.33 \\
12 & 67 female & 1.1 & 91 & 0.58 \\
13 & 38 female & 1.1 & 77 & 0.44 \\
14 & 56 female & 0.8 & 62 & 0.42 \\
15 & 63 male & 1.9 & 263 & 0.89 \\
16 & 45 male & 1.7 & 207 & 0.72 \\
17 & 55 male & 2.5 & - & 0.70 \\
18 & 59 male & 1.1 & - & 0.07 \\
19 & 61 male & 1.1 & - & 0.82 \\
\hline
\end{tabular}

Table 2 Bending test of the vault of the human kull

\begin{tabular}{cccc}
\hline Material & Age \& Sex & $\begin{array}{c}\text { Young's modulus } \\
\left(\mathrm{kg} / \mathrm{mm}^{2}\right)\end{array}$ & $\begin{array}{c}\text { Bending strength } \\
\left(\mathrm{kg} / \mathrm{mm}^{2}\right)\end{array}$ \\
\hline dried & 16 female & 357 & 6.86 \\
& 20 female & 339 & 5.81 \\
35 female & 427 & 10.01 \\
& 45 male & 517 & 8.59 \\
& 47 male & 325 & 4.72 \\
& 7 female & 237 & 5.78 \\
fresh & 20 female & 384 & 7.10 \\
& 22 male & 840 & 10.05 \\
& 28 male & 262 & 4.33 \\
& 31 female & $1137 *$ & $17.20^{*}$ \\
& 34 female & 537 & 6.60 \\
& 42 female & 201 & 6.59 \\
& 60 male & 393 & 5.61 \\
& 62 male & 395 & 4.64 \\
\hline & mean & $401 \pm 159$ & $6.67 \pm 1.81$ \\
& &
\end{tabular}


Table 3 Comparison of various materials

\begin{tabular}{lcc}
\hline Materials & $\begin{array}{c}\text { Young's modulus } \\
\left(\mathrm{kg} / \mathrm{mm}^{2}\right)\end{array}$ & $\begin{array}{c}\text { Bending strength } \\
\left(\mathrm{kg} / \mathrm{mm}^{2}\right)\end{array}$ \\
\hline human skull & & \\
vault & 401 & 6.7 \\
optic canal & 172 & 0.6 \\
monkey skull & 557 & 8.3 \\
dog palatines & 323 & 5.5 \\
\hline FRP & 600 & 6 \\
japanese cypress & 750 & 7 \\
duralmin & 7000 & 30 \\
wrought iron & 21000 & 38
\end{tabular}
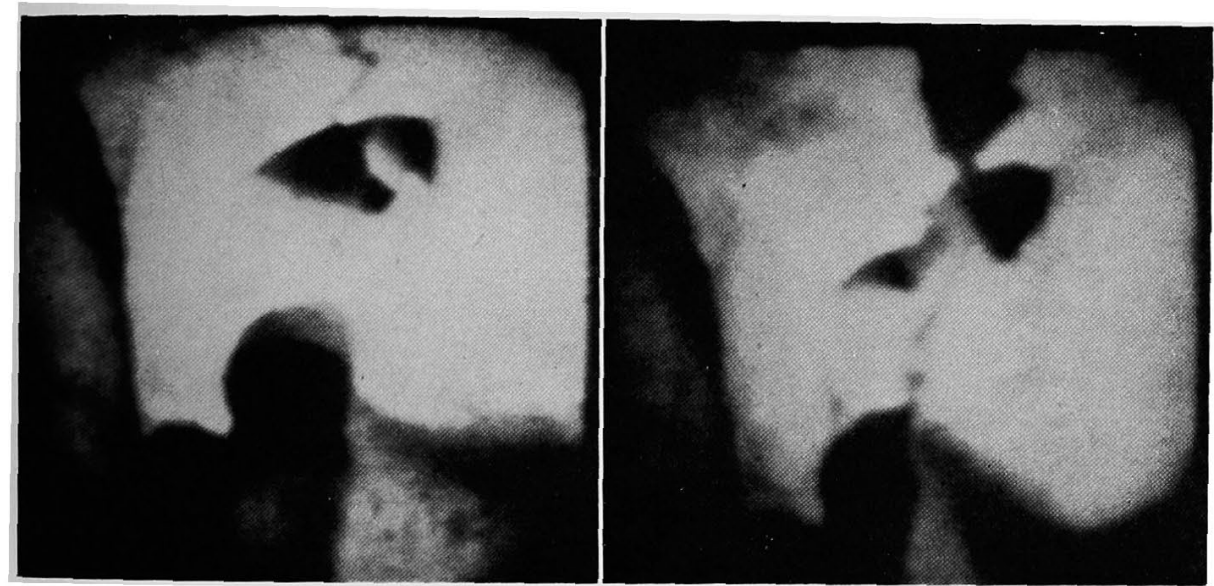

Fig. 5 The destruction of the optic canal was clearly seen in the movie frames through fiberscopy.

individuals the canal can be destroyed easily by a trivial impact. The configuration and the volume of the upper wall vary with the individual. Accordingly fracture lines differ in each case becuase of the sandwitch structure of compact and spongy zone.

\section{5) Fiberscopy at the moment of impact}

Next experiments were direct observations of the fracture by a fiberscope which was inserted through the foramen magnum to observe from behind the process of destruction of the optic canal. One example was shown in Fig. 5 adopted from the movie frames. In this case the upper wall of the optic canal was clearly seen broken, which might contused the optic nerve. But in other cases fracture lines were not seen in the upper wall, but in the lateral portion of the canal.

These experiments showed that the optic canal was fragile and that it could be easily fractured. 


\section{Experiments and Results (II) The injury of the optic nerve}

1) Evaluation of intraorbital pressures in case of rigid skull

There are two theories which explain the injury of the brain: pressure gradient theory (cavitation theory) and shear strain theory. These theories can be applied to the injry of the optic nerve. So the experiments seem worth while.

To confirm these problems intracranial and intraorbital pressures at the moment of impact were measured. Crushable human head models were used?). The head models were made in order to give a thorough simulation of mechanical properties of human head. The skulls of the model were made up of fiberglass reinforced polyester and the scalp was made of thiokol rubber. These models were equipped with three dimensional accelerometers and with many pressure sensors in the intracranial, in-

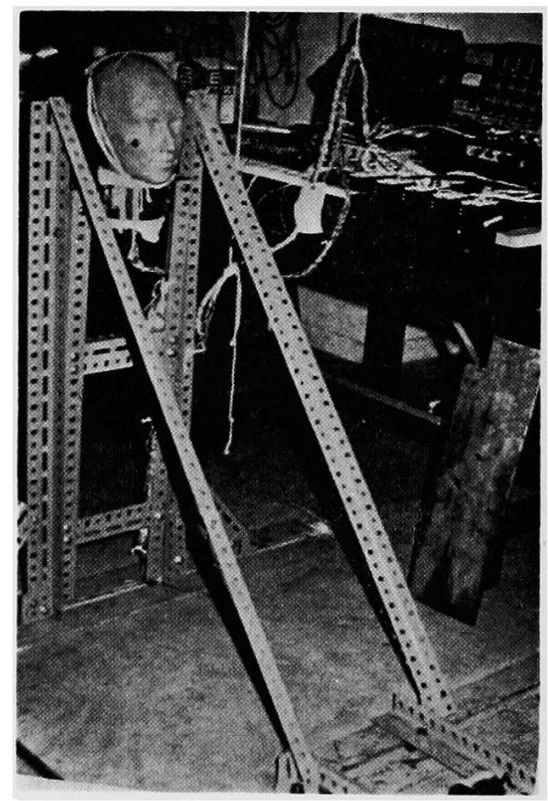

Fig. 6 A crushable head model was used to detect the intracranial, intraorbital, and intraspinal pressures.

traorbital, and intraspinal spaces. The values of the pressure were detected simultaneously in the frontal pole, the intraorbital space, the occipital pole, the base, and the cervical space etc. (Fig. 6). So the pressure gradient in the intracranial, intraorbital, and intraspinal spaces can easily be obtained. The results were almost the same as in the theoretical calculation. For example in the frontal impact peak acceleration $(\mathrm{Gx})$ of the head was $34 \mathrm{G}$, while the pressure at the frontal pole and at the intraorbital space was 0.39 and $0.38 \mathrm{~kg} / \mathrm{cm}^{2}$ in positive pressure and the pres- 


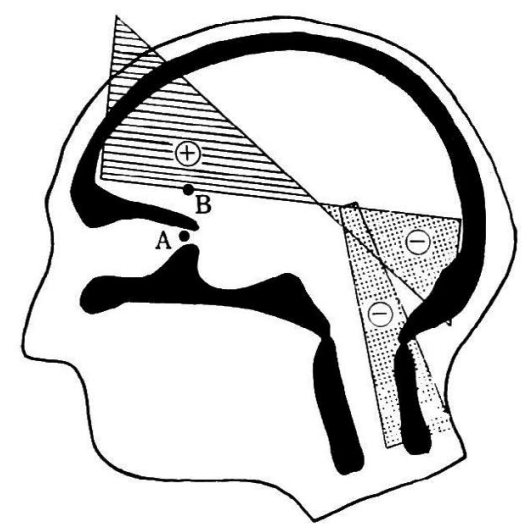

Fig. 7 A diagram of the pressure gradients. Intraorbital pressure (A) is a part of the intracranial pressure (B).

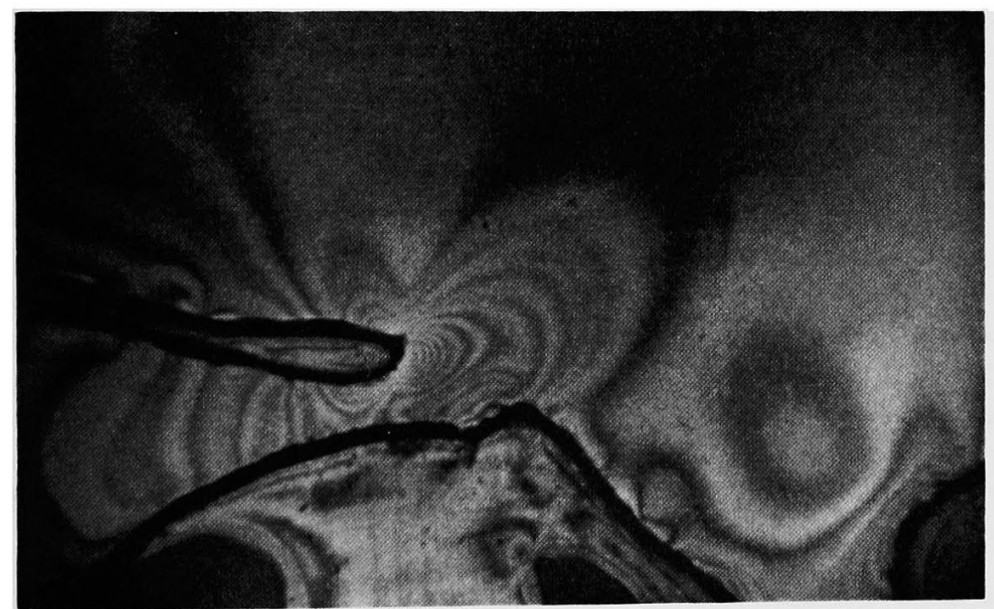

Fig. 8 Isochromatic lines appreared around the optic canal in the photoelastic model in the static experiments.

sure at the occipital pole and at the cervical space was 0.33 and $0.27 \mathrm{~kg} / \mathrm{cm}^{2}$ in negative pressure. In such degree of impact force the skulls can be considered to be rigid. The value of the pressure is equal to the theoretical value and is parallel to that of acceleration. The value of the pressure in the intraorbital space does not exceed that in the frontal pole. The diagram is shown in Fig. 7.

2) Photoelastic experiments in case of elastic skull model

Photoelastic experiments were performed to investigate the stress pattern of the optic nerve in case of elastic deformation of the skull. The models were made of epoxy resin or acrylate plate for the skull and of polyurethane or $8-12 \%$ gelatin for the brain2). The configurations of the models were based upon the sagittal plane of the 


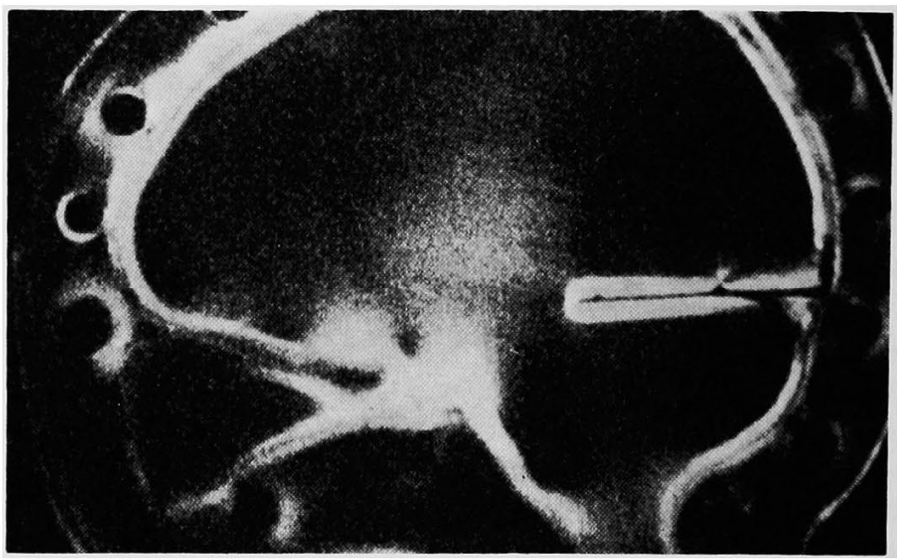

Fig. 9 The strains concentrated around the optic canal in the dynamic photoelastic experiments.

skull cut obliquely through the optic canal. The models were $2 \mathrm{~cm}$ in thickness. In the first experiments, the models were compressed statically in the antero-posterior direction. One of the results are shown in Fig. 8. Isochromatic lines were concentrated to the optic canal, especially to the upper wall of the cranial oriffice of the optic canal. The center of the isochromatic lines coincided with the usual place of the lesion known from the clinical experience. Next position where the isochromatic lines concentrated was just the surface of the sella, which means the lower surface of the chiasm, the same position where Walsh and Lindenberg ${ }^{9)}$ proved wedge-shaped contusion necrosis in the pathological study.

Dynamic tests were added using frontal impacts. The models were dropped to the floor or were crushed against the wall by guide wires or by rotation of the models around the neck. Fig. 9 is drawn out from one of the frames of high speed $16 \mathrm{~mm}$ movie films. The strains concentrated around the optic canal.

\section{Discussion}

These experiments explain on the mechanical basis why traumatic injury of the optic nerve or blindness occurs on one side at the frontal blow. The experiments showed that the strains were marked only on the ipsilateral side of the blow and were negligible on the contralateral side. In some cases the strains exceeded $1000 \mathrm{X}$ $10^{-6}$ even in a small amount of load. The clinical data indicate that there were so many fractured cases even in minor injuries. Static compression tests showed that in some cases fracture of the optic canal occurred in $60 \%$ level if it was compared with the skull of the vault. The same results were obtained in case of dropping test. Besides, bending tests showed that Young's modulus and bending strength of the bone of the upper wall of the optic canal were about half and one-tenth of the corresponding value of the vault of the skull. So it was found that the optic canal was fragile and that it 
could beeasily fractured. As is well known, the upper wall of the optic canal is thin, which is to be seen by transillumination of the base of the skull. Thickness of the bone is roughly parallel to the strength of the canal. However, attention must be paid to the fact that the structure around the optic canal differ with individuals. In some cases fracture occurred not in the upper wall of the optic canal but in the lateral wall, where the fracture of the canal cannot be detected by routine roentgen study. In this experiment, both fresh cadaver materials and dried cadaver skulls were used. The difference between them was quite negligible.

Once the fracture has occurred, does injury of the optic nerve occur in all cases? One may not answer this question accurately. However, fiberscopy at the moment of destruction of the optic canal revealed clearly that fracture dislocation occurred in some cases and that the optic nerve may be cut by the edge of the fractured bone. Even without dislocation, momentary depression of the upper wall of the optic canal may occur at the moment of impact. Photoelastic experiments ${ }^{4)}$ proved that stress patterns appeared mainly around the optic canal and the suprasellar region and would likely to cause the damage to the optic nerve and the chiasm. Anatomical study has shown that the sheath of the optic nerve is firmly and tightly attached to the upper wall of the optic canal, so the strains of the bone are easily conducted to the optic nerve, where the disruption of the nerve fibers and/or vascular damages may occur by neuro-neural strain and/or neuro-vascular strain to cause secondary edema.

If the skulls are rigid and elastic deformation does not happen, pressure gradient at the moment of impact should be tested. The experiments showed that intraorbital pressure did not exceed the pressure of the frontal pole. Pressure gradients were as Hayashi ${ }^{2}$ had shown in his theory. He proposed that the pressure gradient is not affected by the configuration of the cut area. These experiments confirmed this theory and intraorbital space seems to act as a part of the intracranial space in this model. Crush experiments ${ }^{1)}$ of monkeys also showed that brain contusions occurred when negative pressure exceeded $-1 \mathrm{~kg} / \mathrm{cm}^{2}$, the cavitation level. To apply this to human head, the acceleration should be $150 \mathrm{G}$ on theoretical analysis. This value means a heavy blow. This is not compatible with the fact that the traumatic blindness occurs even in the trivial blow. Besides, the experiments showed that the skull was not a rigid body but was a brittle elastic body ${ }^{8}$. The spring rate was $600 \mathrm{~kg} / \mathrm{mm}$ on the average. When the fracture of the optic canal is discussed, pressure gradients are out of question and the significance of the elastic deformation of the optic canal must be emphasized. The elastic deformation of the optic canal is the trigger of the injury of the optic nerve. The mechanism should be called momentary depression of the orbital roof and the optic canal.

\section{Summary and Conclusions}

These studies were performed to investigate the mechanism of the fracture of the optic canal and to clarify the threshold of the impact force, because this is thought to be closely relevant to the optic nerve injury. 
1) The stress coat method revealed that when an impact force was given to a skull in the frontal area, stress lines appeared on the roof of the orbit towards the optic canal on the side ipsilateral to the blow. This means that the roof of the orbit and the optic canal are depressed from above at the moment of impact.

2) After strain gauges were patched bilaterally to the upper walls of the optic canals, the skull was compressed statically and the stress-strain curves were drawn. Strains were recorded especially on the compressed side, showing that the upper wall of the optic canal was depressed, while the other side showed little effect of strain. The skulls were destroyed by $300-500 \mathrm{~kg}$ load.

3) Dynamic tests were added, using the skull filled with gelatin and covered with silicon skin. The behavior of the upper wall of the optic canal was the same as in the static tests. Fracture of the vault occurred in $60-100 \mathrm{~cm}$ fall on a steel plate. Maximum load factor was greater than 110. The optic canal was destroyed in 20$60 \mathrm{~cm}$ fall and the load factors were $70-100$.

4) Bending tests were performed on the bone of the upper wall of the optic canal. Young's modulus was $172 \mathrm{~kg} / \mathrm{mm}^{2}$ and bending strength was $0.6 \mathrm{~kg} / \mathrm{mm}^{2}$ on the average. The former was about half and the latter was one-tenth of the corresponding value of the vault of the skull. The upper wall varies in thickness and in some individuals the canal can be destroyed easily by a trivial impact.

5) A fiberscope was inserted through the foramen magnum, to observe from behind the process of destruction of the optic canal.

6) Intracranial pressures were detected in rigid skull models. Intraorbital pressure did not exceed the pressure of the frontal pole. It seemed to be a part of the intracranial pressure gradient which was the same as the theoretical analysis. The injury of the optic nerve is not likely to occur by the pressure change at the moment of the impact.

7) Photolelastic experiments showed that the isochromatic lines appeared around the optic canal.

8) These experiments showed that the optic canal was fragile and that it could be easily fractured. With a lethal blow, the canal may be destroyed and split apart, and the optic nerve may be cut by bone fragments. In a minor impact, momentary depres sion of the optic canal may probably occur with or without fracture, and give the optic nerve and its vascular system a damage by shearing effect. Irreversible visual loss in brought about by the secondary edema following the depression. Significance of the elastic deformation of the optic canal should be emphasized.

Acknowledgement: The authors wish to thank Prof. Tsuyoshi Hayashi and his associate, Department of Aeronautics, Faculty of Engineering, University of Tokyo, for their kind suggestion to the experiment and Hazime Kobayashi, Department of Mechanical Engineering for Production, Faculty of Engineering, University of Tokyo, for his kind help to detect the intracranial pressure in the skull models. This work was supported in part by Ministry of Education granting aid for developmental scientific research No. 7238 and in part by Japan Automobile Research Institute grants. 


\section{References}

1) Hashizume, K.: A study of experimental brain injury. Relation between intracranial pressure gradient and brain injury. Brain Nerve, 24, 991-1002, 1972. (Jap.)

2) Hayashi, T.: Study of intracranial pressure caused by head impact (2nd report). J. Fac. Engineer. Univ. Tokyo (B), 30, 117-124, 1969.

3) Hirakawa, K.: Mechanical study on the fracture of the optic canal. Brain Nerve, 22, 697-711, 1970. (Jap.)

4) Hirakawa, K., Hashizume, K., Fuchinoue, T., Matsui, T., Nakamura, N., and Sano, K.: Analysis of traumatic brain injury by photoelastic model. Jap. J. Surg. Soc., 73, 1130-1133, 1972. (Jap.)

5) Hirakawa, K., Nakamura, N., Masuzawa, H., Hashizume, K., and Sano, K.: An analysis of the fracture of the skull and the orbit-stress coat method and its clinical application. Brain Nerve, 21, 963-973, 1969 (Jap.)

6) Hirakawa, K., Nakamura, N., Masuzawa, H., Hashizume, K., and Sano, K.: Head impact and buffer capacity of human scalp and its simulation. Jap. J. Ergonom., 6, $71-80,1970$. (Jap.)

7) JARI technical memorundum: A study on the injury and the protection of the human brain in the crush impact. Japan Automobile Rescarch Institute, Inc., 1970. (Jap.)

8) Masuzawa, H.: Engineering aspects of human skull fracture. Experimental study and theoretical consideration on brain damage. Brain Nerve, 24, 547-561, 1972. (Jap.)

9) Walsh, F. B. and Lindenberg, R.: Die Veränderung des Sehnerven bei indirectem Trauma. Sautter, H. ed. Entwiclung und Fortschritt in der Augenhk. S. 83-107, Enke, Stuttgart, 1963. 